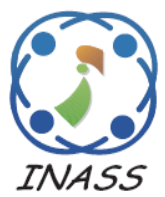

\title{
Power Quality Improvement in Hybrid Power System Integration Using FPA and IC Controller
}

\author{
Shweta Sengar ${ }^{1 *}$ \\ Apurva Thakur ${ }^{1}$ \\ ${ }^{I}$ ITS Engineering College, Greater Noida, India \\ * Corresponding author's Email: shwetasengar17@gmail.com
}

\begin{abstract}
Renewable Energy Sources (RES) are widely used to support higher energy demand caused by industrialization and increased population. The voltage quality of the desired systems affected due to the RES with fluctuating outputs and power demand from the load. In this research, a combination of two or more RES named Hybrid RES is developed to fulfil the higher energy demand. An effective Energy Management System (EMS) is developed using a combination of the Flower Pollination Algorithm (FPA) and Incremental Conductance (IC) method. Three different sources such as a Photovoltaic (PV) module, wind turbine, and battery are used to create an efficient EMS for the grid-connected system. The FPA is used to control the switching between the wind turbine and battery storage system. Also, the IC method is used to trigger the switch of DC-DC converter to achieve stable power from the PV/wind/battery system. The performance of the FPA-IC controller is analyzed in terms of Maximum Power Point Tracking (MPPT) voltage \& current, PV power, Wind power, battery power, and Total Harmonic Distortion (THD). The simulation results of FPA-IC controller are compared with existing RES designs Model Predictive Current and Power- Model Predictive Voltage and Power (MPCP-MPVP), Fuzzy Logic Control based Proportional Integral (FLCPI), and Model Predictive Power and Voltage Control (MPPVC). The THD of the proposed FPA-IC controller is $0.71 \%$, which is very less when compared to the existing approach.
\end{abstract}

Keywords: Energy management system, Flower pollination algorithm, Incremental conductance, Renewable energy source, Total harmonic distortion.

\section{Introduction}

Nowadays, Renewable Energy Sources (RES) are used widely to fulfill the higher power demand of the modern world. The usage of non-renewable energy sources is gradually decreased due to the impacts of global warming and usage of RES [1]. The RES is considered an important energy source to fulfill the electricity requirements in remote and isolated areas. In present economic development, RES provides clean, affordable, and proper energy supply to the desired system [2, 3], and the advantages of the RES are eco-friendly and limitless. The different types of RES are tidal power, solar, wind, biomass, hydroelectric and geothermal energy [4, 5]. Also, the PV systems have various benefits like lack of noise, deficiency of fuel cost, high dependability, and simplicity in allocation. Besides this, a cost-effective solution has been provided in rural areas where the building has integrated with a long transmission system. [6, 7].

The major drawback of the RES is mainly dependent on the topological condition of certain sites and its outputs are sporadic. Moreover, a single RES does not satisfy the entire energy demand of the load, so, the continuous power can be delivered by integrating two or more RES in a single unit [8]. Therefore, a reliable, flexible, and cost-effective EMS has been designed by integrating the modular power generation and storage devices named hybrid systems [9]. The major challenges faced in the RES based EMS are: wind and solar are omnipresent and environmental friendly in nature. However, the aforementioned systems failed to provide continuous power to the system because of their irregular features [10]. The gap between the PV source and load is balanced by the battery storage in EMS. The 
long-time energy requirements are not satisfied by the PV/Wind/battery-based grid due to the limited battery capacity $[11,12]$. The EMS process is quite difficult due to the formation of continuous variation in RES and variable loads [13, 14]. The main contributions of this study are presented as follows:

- A combination of RES with battery (i.e., energy storage system) significantly minimizes the PQ features. Moreover, higher energy density can be achieved by incorporating the battery into the grid.

- A combination of FPA and IC controller is designed to develop an effective power management to fulfill the load demand.

- FPA is considered due to its higher convergence rate that effectively changes the switching process to reduce the THD level.

The organization of this research paper is presented as follows: The literature survey of existing researches related to the $\mathrm{PV} /$ wind/battery system is given in Section 2. Section 3 presents modeling of PV module, wind turbine, and battery. The proposed EMS system using the combination of FPA and IC is discussed in Section 4. The experimental and comparative results of the FPA-IC is presented in Section 5. Finally, the conclusion is given in Section 6.

\section{Literature survey}

This section provides the literature survey about the recent researches related to the PV/wind/battery system.

M. De, G. Das, K. K. Mandal [15] presented a Meta dynamic Flower Pollination Algorithm (MFPA) for operative power flow controlling in gridconnected hybrid system integrating cost-effective and conservational generation planning. The examination achieved that the projected FPA is highly modest for generation planning and power management in grid. However, self-fertilization consumes a drawback. In recent days, several investigators have clarified that self-pollination is not ideal for inherent recombination.

Jha and Kumar [16] introduced a control algorithm in an energy storage system to support the microgrid network during the rapid change of load. The battery power was established by formulating the control strategy that handles the state of charge (SOC). This designing factor considers the voltage issues in RES and storage devices, but it not concentrated on the power management issues in the hybrid system.

Shan [17] presented Model Predictive Control (MPC) strategy for PV-wind-battery-based microgrid.
The RES output was smoothened and DC/AC bus voltage was maintained by controlling the $\mathrm{AC} / \mathrm{DC}$ converter and $\mathrm{dc} / \mathrm{dc}$ converter. The $\mathrm{dc}$ bus voltage was maintained with fewer oscillations using the MPC technique. While the system operating at transition mode, the filter capacitor connection and disconnection causes the harmonics (spikes in current) in the load side.

$\mathrm{Hu}$ [18] presented the coordinated control strategy for the micro-grid with hybrid energy resources and AC/DC loads. For AC/DC interlinking converter, the Model Predictive Power and Voltage Control (MPPVC) method was developed to maintain the stable $\mathrm{AC} / \mathrm{DC}$ bus voltages. In the interlinking converter control, the developed control method requires only less tuning work than the conventional cascade linear control. The sudden disconnection in the hybrid energy sources causes the spike (harmonics) in the grid current which leads to minimize the power extraction.

Basaran [19] demonstrated the Fuzzy Logic Control (FLC) for PV and wind power generator present in the power system. In this system, the energy storage devices were essential, due to the continuous energy demand. Also, the control unit was designed to operate the PV-wind-battery system in both on/off-grid, and FLC control was used as a control unit. In case of the converter is operated in less power than the nominal power, the voltage and current value will decrease which increases the harmonic distortion.

Kumar [20] has demonstrated an efficient energy management system for a small-scale hybrid source based micro-grid to test the functionality of the distribution system. The main objective was to deliver constant power to the load, under different generating conditions. But the load is kept fixed to observe the operation performance of renewable energy conversion systems and the battery storage system for a different amount of power generations from RES. This observation will be a difficult task to achieve if there is a change in load.

In order to increase both the capacity of PV arrays and maintain power quality, it's necessary to comply with some techniques. Therefore, the system operation and system stability should be examined with FPA-IC technique when PV modules are interface with power grid.

\section{Hybrid energy system components}

In this research, hybrid renewable energy sources such as PV, Wind [21] are used with one storage devices name called Battery. The specifications for 
Table 1. Specifications of PV module

\begin{tabular}{|c|c|}
\hline Parameters & Value \\
\hline Cells per module (Ncell) & 96 \\
\hline Current Isc (A) & 5.58 \\
\hline Diode ideality factor & 0.94504 \\
\hline Diode saturation current (A) & $6.301410-10$ \\
\hline Light generated current IL (A) & 6.0092 \\
\hline Maximum power (W) & 305.226 \\
\hline Open circuit voltage Voc (V) & 64.2 \\
\hline Temperature coefficient (\%/deg.C) & 0.061745 \\
\hline Voltage at maximum power point & 54.7 \\
\hline
\end{tabular}

Table 2. Specifications of wind turbine

\begin{tabular}{|c|c|}
\hline Parameters & Value \\
\hline Base rotational speed $(\mathrm{pu})$ & 1 \\
\hline Base wind speed (m/s) & 9 \\
\hline $\begin{array}{c}\text { Inertia constant, friction factor, [H(s), } \\
\mathrm{F}(\mathrm{pu})]\end{array}$ & $5.04,0.01$ \\
\hline Magnetizing inductance Lm $(\mathrm{pu})$ & 6.77 \\
\hline Maximum pitch angle $(\mathrm{deg})$ & 45 \\
\hline Maximum power at base wind speed & 1 \\
\hline rate of change of pitch angle $(\mathrm{deg} / \mathrm{s})$ & 2 \\
\hline Nominal mechanical power $(\mathrm{W})$ & $50 \times 103$ \\
\hline Pitch angle controller gain: $[\mathrm{Kp} \mathrm{Ki}]$ & 5,25 \\
\hline
\end{tabular}

the respective sources are described in the following section.

\subsection{Photovoltaic array}

The PV system's voltage and current are determined by connecting the PV panel either in parallel or in series connection. The specifications of PV modules are represented in Table 1.
Table 3. Specifications of battery

\begin{tabular}{|c|c|}
\hline Parameters & Value \\
\hline Battery response time (s) & 0.5 \\
\hline Discharging current [i1] (A) & 50 \\
\hline Fully Charged Voltage (V) & 588.9831 \\
\hline Initial State of Charge (\%) & 10 \\
\hline Internal resistance (Ohms) & 0.7693 \\
\hline Maximum capacity (Ah) & 7 \\
\hline Nominal discharge current (A) & 1.3 \\
\hline Nominal voltage (v) & 500 \\
\hline Rated capacity (Ah) & 6.5 \\
\hline
\end{tabular}

\subsection{Wind turbine}

The wind turbine output power is mainly based on the rated speed, cut off voltage and cut in voltage. The specification for wind is represented in Table 2.

\subsection{Battery model}

The RES's output power varies due to varying environmental conditions, so the battery source is included as a backup. The specification for a battery is represented in Table 3.

\section{Proposed system}

In this study, an effective energy management strategy is designed using two different RES and one storage device. The Two different RES are used for EMS, those are PV module and wind turbine. Additionally, a storage device battery is used to store the excess power from the PV module and wind turbine. The block diagram of the grid-connected RES with FPA-IC controller is presented in Fig. 1.

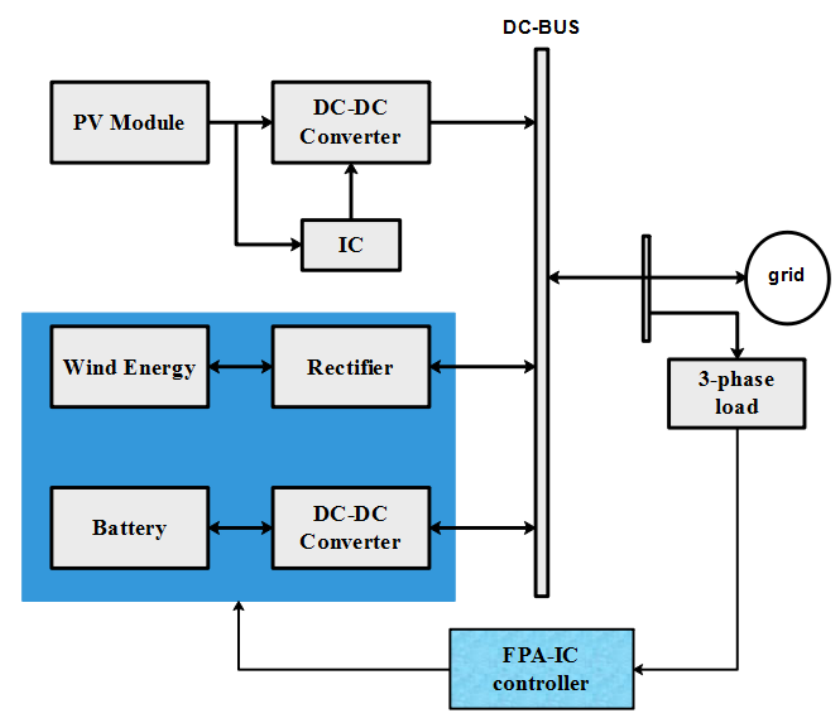

Figure. 1 Block diagram of grid-connected FPA-IC controller 


\subsection{Flower pollination algorithm (FPA)}

Step 1: Initially, the cross-pollination is referred to as the global pollination process which is executed over levy flight. The levy flight is executed by communicators that carry pollens. Eq. (1) shows the characteristics of global pollination.

$$
y_{j}^{t+1}=y_{j}^{t}+\varepsilon L(\lambda)\left(O^{*}-y_{j}^{t}\right)
$$

where solution $j$ presented in iteration $t$ which is represented as $y_{j}^{t}$; the global optimum solution in cross-pollination is $O^{*}$; the control step's scaling factor is $\varepsilon$; the displacement of levy flight related to the individual flower is denoted as $L(\lambda)$ which is expressed in Eq. (2).

$$
L(\lambda)=\frac{\lambda \Gamma(\lambda) \cdot \sin (\lambda \pi / 2)}{\pi} \cdot \frac{1}{S^{1+\lambda}} ;\left(S \gg S_{0} \gg 0\right)
$$

where, the $\lambda$ is fixed taken as 1.7. the standard gamma function is represented $\Gamma(\lambda) . S$ is specified in the aforementioned equation is expressed in Eq. (3).

$$
S=\frac{\mu}{|v|^{1 / \lambda}}
$$

where normal distribution coefficients are $\mu$ and $v$, $\mu \sim M\left(0, \sigma^{2}\right)$ and $v \sim M(0,1)$. Eq. (4) expresses the $\sigma^{2}$.

$$
\sigma^{2}=\left[\frac{\Gamma(1+\lambda)}{\lambda \Gamma((1+\lambda) / 2)} \cdot \frac{\sin (\lambda \pi / 2)}{2^{(\lambda-1) / 2}}\right]^{1 / \lambda}
$$

Step 2: Flower's local pollination process is specified as self-pollination. The local pollination process is specified in Eq. (5).

$$
y_{j}^{t+1}=y_{j}^{t}+\xi\left(y_{k}^{t}-y_{l}^{t}\right)
$$

where the various flower's pollen from the same plant are represented as $y_{k}^{t}$ and $y_{l}^{t}$. Then the $\xi$ defines the

Table 4. Specifications of FPA algorithm

\begin{tabular}{|c|c|}
\hline Parameters & Value \\
\hline Dimension & 5 \\
\hline Fitting parameter- $\gamma_{1}$ & 1 \\
\hline Fitting parameter- $\gamma_{2}$ & 3 \\
\hline Levy flight & 1.7 \\
\hline Lower bound & -5 \\
\hline Number of iterations & 100 \\
\hline Number of population & 50 \\
\hline Switch probability & 0.6 \\
\hline Upper bound & 5 \\
\hline
\end{tabular}

uniformly distributed random numbers, $\xi \epsilon[0,1]$.

Step 3: Switch probability i.e., $q \epsilon[0,1]$ controls transformation between the local and global pollination.

The process of solving MPPT using FPA is explained in the following section and its specifications are represented in Table 4.

\subsubsection{Controlling of wind turbine and battery}

In this study, the power extracted from the PV module, wind turbine, battery, and load demand is given as input to FPA to adjust the ON/OFF states of wind and battery. The optimization of MPPT using FPA is given in the following steps.

1. Initially, FPA parameters are initialized, such as Duty cycle (i. e., $y_{j}, j=1,2, \ldots, m, 0<$ $\left.y_{j}<1\right)$, the maximum amount of iterations $(M=50)$, count flag of iteration $(t=0)$ and switch probability $(q=0.6)$.

2. Duty cycles are randomly generated and it is transferred to the DC/DC converter.

3. In this step, the duty cycle achieves higher power $O^{*}$ and respective optimal duty cycle $\left(y^{*}\right)$ is determined in the FPA.

4. Compute the duty cycle's average value $\left(f_{\text {avg }}\right)$ that captures the output power and average value $\left(f_{\text {avg }}^{*}\right)$ greater than $f_{\text {avg }}$.

5. When $Q_{j}$ is higher than the $f_{\text {avg }}^{*}$, the subsequent duty cycle is obtained from the local pollination. If $Q_{j}$ is lesser than $f_{a v g}^{*}$, the duty cycle is obtained from global pollination. The duty cycle updates of global and local pollination are given in the Eqs. (6) and (7) respectively.

$$
\begin{gathered}
y_{j}^{t+1}=y_{j}^{t}+\varepsilon L(\lambda)\left(O^{*}-y_{j}^{t}\right) \\
y_{j}^{t+1}=y_{j}^{t}+\xi\left(y_{k}^{t}-y_{l}^{t}\right)
\end{gathered}
$$

6. FPA's optimization is continued until the system achieves MPP. If FPA does not give an optimum MPP, then optimization is processed again from step 3 to step 6 .

\subsection{IC algorithm}

From the collected literature works, the $\mathrm{P} \& \mathrm{O}$ technique is the best and repeatedly exploited MPPT procedure for attaining maximum power. However, IC procedure was established and depends on the P$\mathrm{V}$ distinctive curve and it regulates the duty cycle of the converter to adjust the operating point of the PV array. The proposed IC is established to conquer the 
disadvantages of the conventional $\mathrm{P} \& \mathrm{O}$ technique. Here, MPP is attained using the association between $\frac{\partial I}{\partial V}$ and $-\frac{I}{V}$, which is stated in Eq. (8).

$$
P=V I
$$

After taking the derivative on Eq. (19) at both sides, it is represented as Eqs. (9) to (11).

$$
\begin{gathered}
\frac{\partial P}{\partial V}=\frac{[\partial(V I)]}{\partial V} \\
\frac{\partial P}{\partial V}=I \frac{\partial V}{\partial V}+V \frac{\partial I}{\partial V} \\
\frac{\partial P}{\partial V}=I+V \frac{\partial I}{\partial V}
\end{gathered}
$$

At MPP, the Eq. (12) is written as

$$
\frac{\partial P}{\partial V}=0
$$

Therefore, the Eq. (13) will be expressed as

$$
\frac{\partial I}{\partial V}=-\frac{I}{V}
$$

So this Eq. (13) is used for controlling the duty cycle of a boost converter. Then, MPPT controls the PWM signal of the inverter until the maximum power is reached. The controller architecture designed in this $\mathrm{PV} /$ wind/battery system using FPA-IC is presented in the Fig. 2. The aim of the controller as shown in Fig. 2, is to transfer all the active power produced by the PV system to the grid and also to produce nil amount of reactive power so that unity power factor is obtained, except when the grid operator requires reactive power.

\section{Simulation results}

Implementation and simulation of the FPA-IC controller in the grid-connected RES are carried out in MATLAB R2018a which is operated in a Windows 8 operating system with an Intel Core i3 processor and 4GB RAM. The Simulink model of the RES with FPA-IC controller is presented in Fig. 3. Next, the performance and comparative analysis are discussed in the following section. Fig. 4 illustrates the produced PV power. Fig. 5 illustrates the delivered wind power.

Table 5 describes the system parameters for the hybrid PV/Wind/Battery system. The following Fig. 4 to 6 denotes the extracted power during the stated simulation conditions.

Table 5. System parameters for FPA-IC

\begin{tabular}{|c|c|}
\hline Parameter & Numerical Value \\
\hline Irradiation $\left(\mathrm{W} / \mathrm{m}^{2}\right)$ & 1000 \\
\hline Temperature $(\% /$ deg. C) & 35 \\
\hline Maximum pitch angle (deg.) & 2.7 \\
\hline Base Wind speed (m/s) & 9 \\
\hline Battery response time (s) & 0.5 \\
\hline Initial State of Charge (\%) & 10 \\
\hline
\end{tabular}

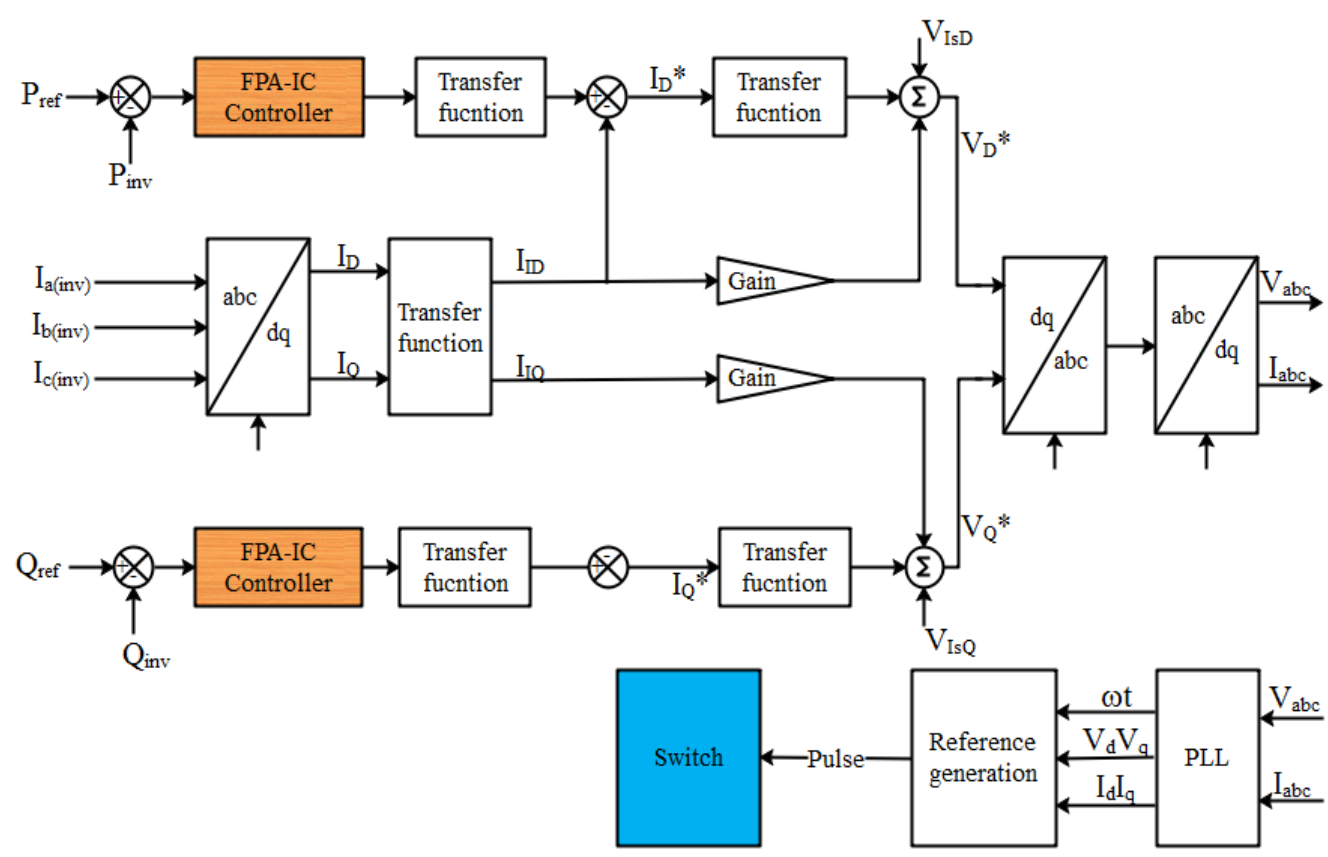

Figure. 2 The architecture of the system using FPA-IC 


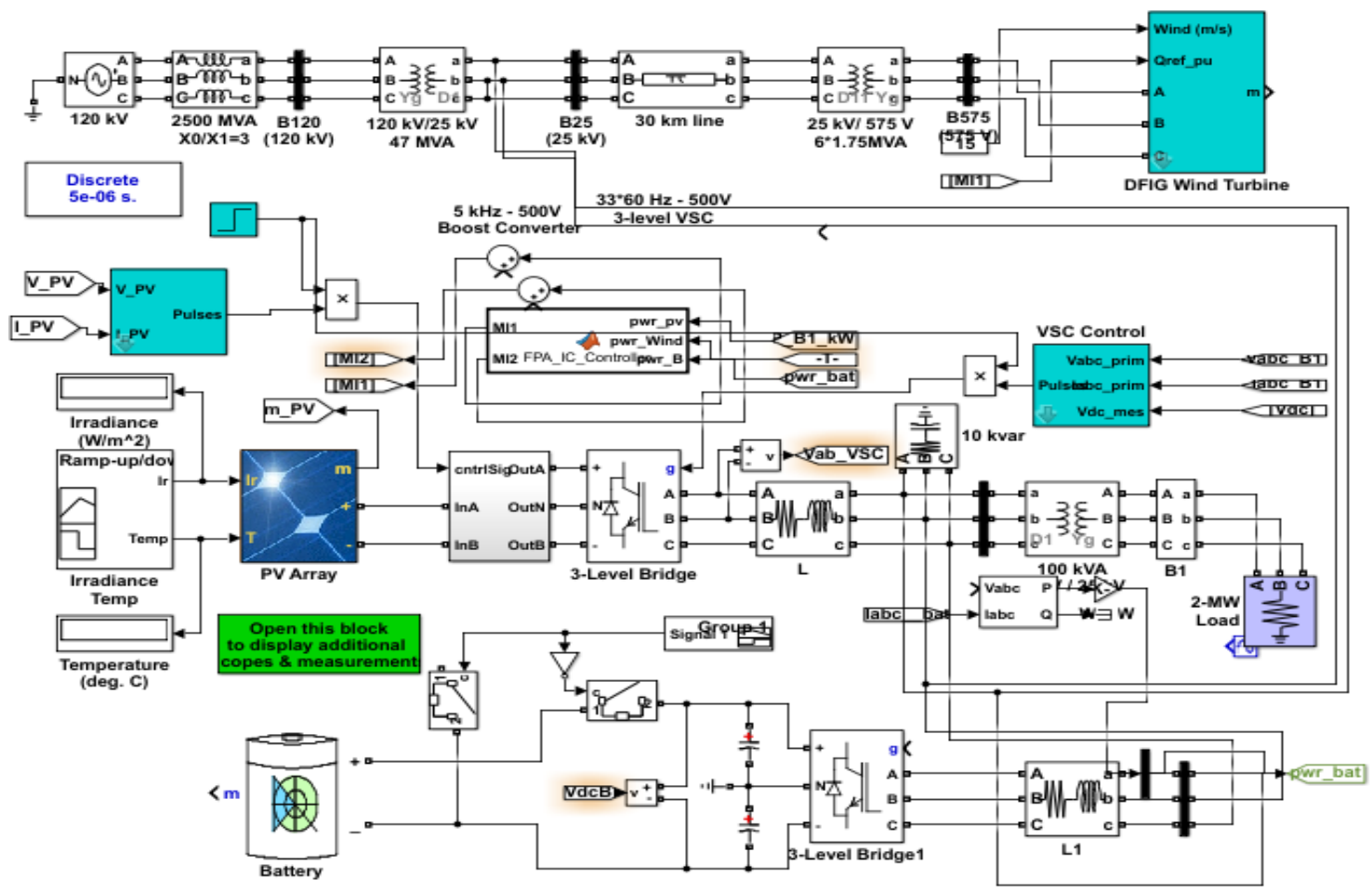

Figure. 3 Simulink model of grid-connected RES using FPA-IC controller

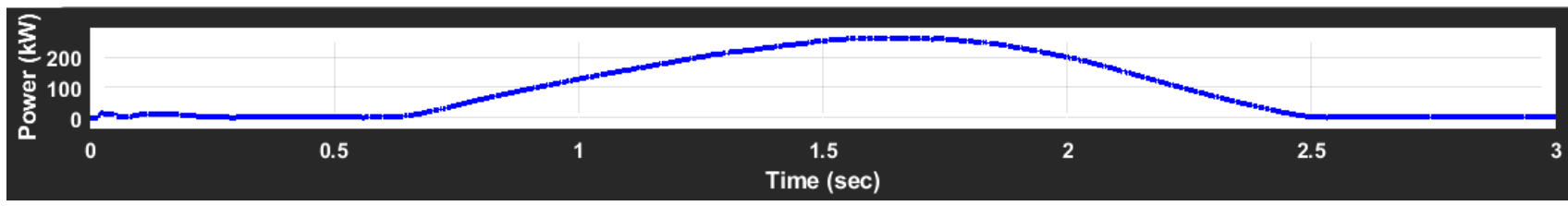

Figure. 4 Power delivered at PV panel

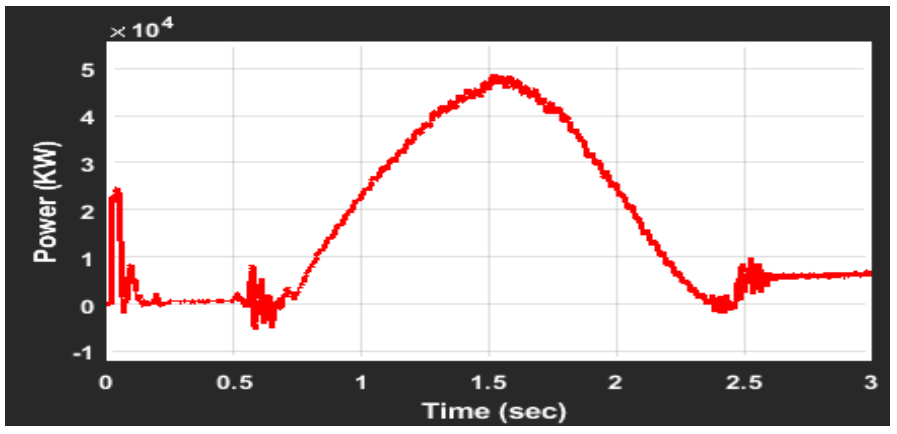

Figure. 5 Power delivered at wind turbine

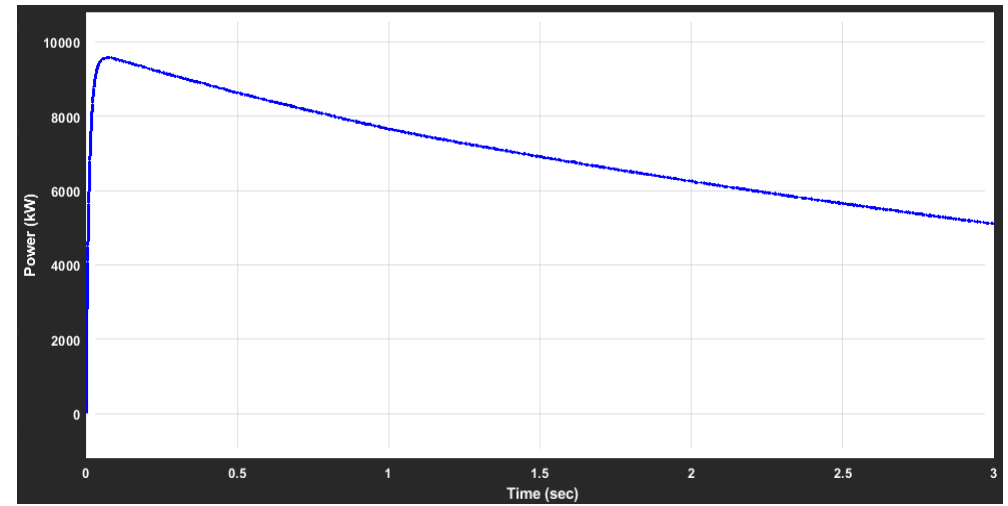

Figure. 6 Energy generation of the battery 


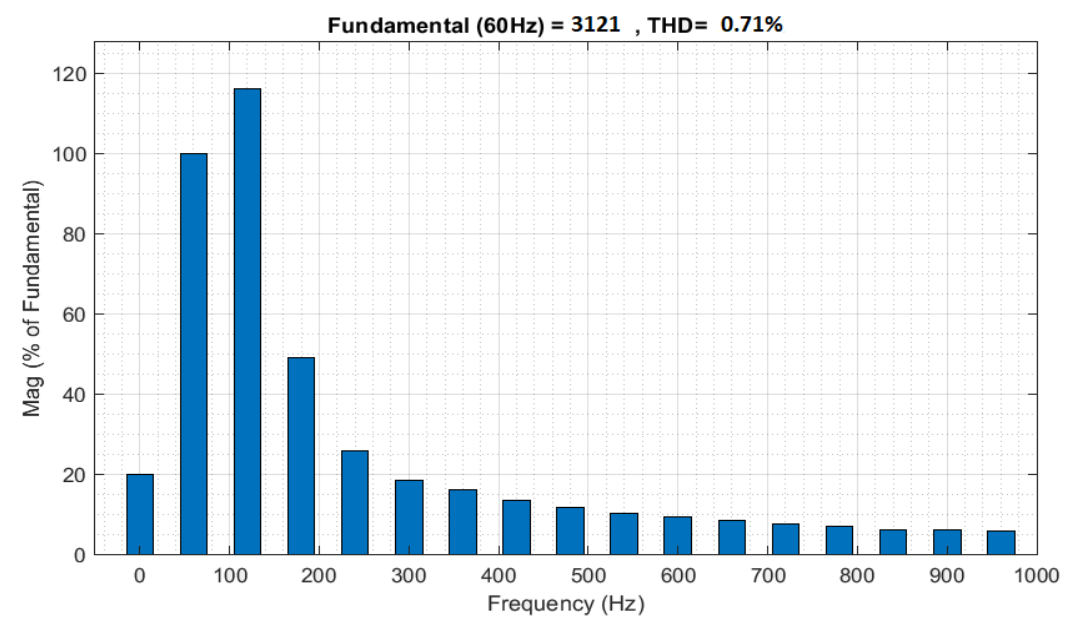

Figure. 7 THD for FPA-IC

Due to that proper scaling factor, duty cycle value gets adjusted, so that the PV achieves peak point to extract maximum power. In the simulation process, behavior of proposed system is tested. This model was considered at different formations and situations of hybrid renewable energy sources availability and different types of consumers at various conditions [19]. Fig. 6 represents the energy generation of the battery source.

Fig. 7 presents THD for FPA-IC as $0.71 \%$ respectively. The THD of the FPA-IC controller is less when compared with the aforementioned controllers.

\subsection{Comparative analysis}

The effectiveness of the proposed FPA-IC controller with grid-connected RES is analyzed by comparing with the existing designs of RES system such as MPCP-MPVP [17] and MPPVC [18].
Table 6. Comparison of THD for FPA-IC and existing methods

\begin{tabular}{|c|c|}
\hline Method & THD (\%) \\
\hline MPCP-MPVP [17] & 1.05 \\
\hline MPPVC [18] & 1.06 \\
\hline FPA & 0.80 \\
\hline INC & 0.92 \\
\hline Proposed FPA-INC & 0.71 \\
\hline
\end{tabular}

Table 6 and Fig. 8 present the THD comparison of FPA-IC controller with MPCP-MPVP [17], and MPPVC [18]. Various values of step size are evaluated and results indicate that the proposed FPAIC reduce THD in the current signal of the PV system significantly. Different step sizes directly influence the effectiveness of the THD reduction, with small step sizes and long filters being the most effective. From the Fig. 9, it clearly shows that proposed

Table 7. Comparison of PV \& wind power

\begin{tabular}{|c|c|c|c|c|c|}
\hline \multirow[b]{2}{*}{ Conditions } & \multirow[b]{2}{*}{ Time (Hrs) } & \multicolumn{2}{|c|}{ PV Power (W) } & \multicolumn{2}{|c|}{ Wind Power $(W)$} \\
\hline & & FLC-PI [19] & Proposed FPA-IC & $\begin{array}{c}\text { FLC-PI } \\
{[19]}\end{array}$ & Proposed FPA-IC \\
\hline \multirow{9}{*}{$\begin{array}{c}\text { PV } \\
\text { Irradiation }-1000 \\
\text { Temperature }-35 \\
\text { Temperature } \\
\text { coefficient }-0.061 \\
\text { Current }-5.58 \mathrm{~A} \\
\text { Wind } \\
\text { Speed }-9 \mathrm{~m} / \mathrm{s} \\
\text { Pitch angle gain }-5 \\
\text { Nominal power - } \\
50 \times 103 \\
\text { Max. pitch angle - } \\
45 \text { ' } \\
\text { Time between } 8.30 \\
\text { AM to 5.30 PM }\end{array}$} & $8.30-9.20$ & 50 & 62.14 & 65 & 80.90 \\
\hline & $9.30-10.20$ & 70 & 74.22 & 85 & 97.42 \\
\hline & $10.30-11.20$ & 150 & 164.94 & 100 & 114.09 \\
\hline & $11.30-12.20$ & 180 & 195.87 & 150 & 201.55 \\
\hline & $12.30-13.20$ & 200 & 205.82 & 120 & 147.15 \\
\hline & $13.30-14.20$ & 175 & 199.61 & 315 & 380.27 \\
\hline & $14.30-15.20$ & 150 & 177.04 & 375 & 399.50 \\
\hline & $15.30-16.20$ & 40 & 64.14 & 520 & 592.18 \\
\hline & $16.30-17.20$ & 20 & 52.91 & 290 & 324.66 \\
\hline
\end{tabular}




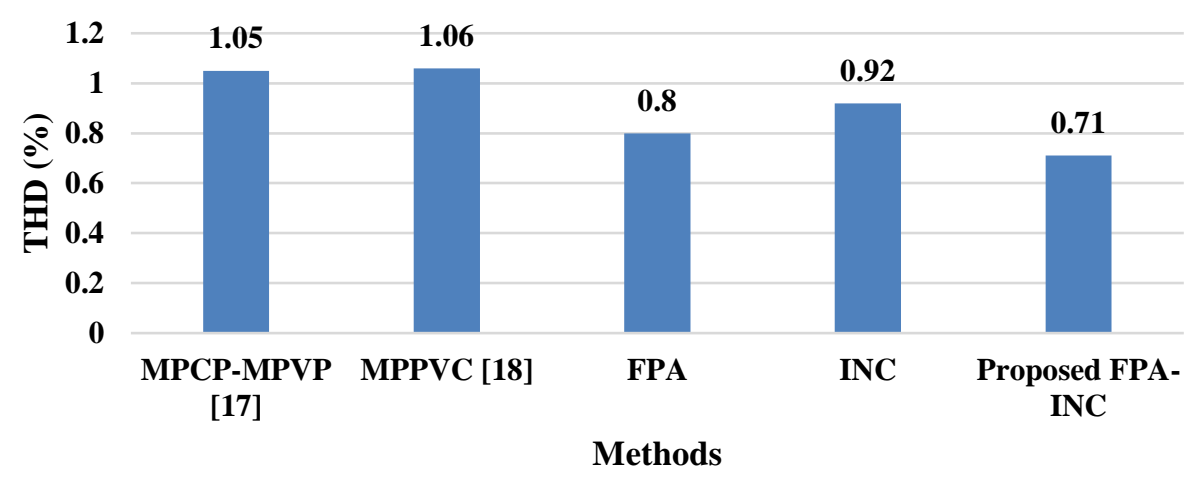

Figure. 8 Graphical illustrations of THD comparison

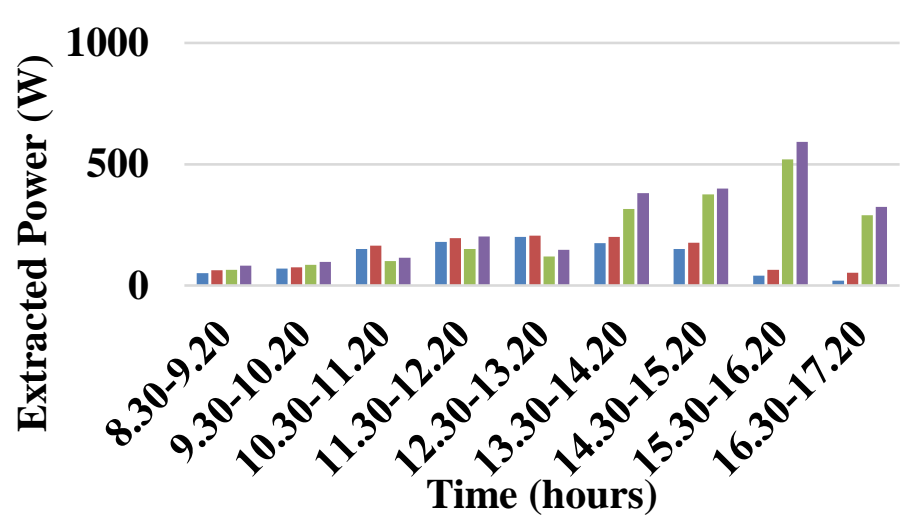

- PV Power (W) FLC-PI [19]

- PV Power (W) Proposed FPA-IC

Wind Power (W) FLC-PI [19]

- Wind Power $(\mathrm{W})$ Proposed FPA-IC

Figure. 9 Graphical illustrations of power comparison

Table 8. Comparison of power for proposed controller

\begin{tabular}{|c|c|c|c|c|c|c|}
\hline \multirow{2}{*}{$\begin{array}{c}\text { Time } \\
\text { Min) }\end{array}$} & \multicolumn{2}{|c|}{ PV Power $(\mathrm{W})$} & \multicolumn{2}{c|}{ Wind Power $(\mathrm{W})$} & \multicolumn{2}{c|}{ Battery Power (W) } \\
\cline { 2 - 7 } & $\begin{array}{c}\text { MPPT } \\
\text { Controller [20] }\end{array}$ & $\begin{array}{c}\text { Proposed } \\
\text { FPA-IC }\end{array}$ & $\begin{array}{c}\text { MPPT } \\
\text { Controller [20] }\end{array}$ & $\begin{array}{c}\text { Proposed } \\
\text { FPA-IC }\end{array}$ & $\begin{array}{c}\text { MPPT } \\
\text { Controller [20] }\end{array}$ & $\begin{array}{c}\text { Proposed } \\
\text { FPA-IC }\end{array}$ \\
\hline 0 & 50 & 69.7842 & 35 & 49.2082 & 2 & 18.0284 \\
\hline 10 & 54.26 & 70.2813 & 42.18 & 53.1083 & -22.2 & 1.6292 \\
\hline 20 & 54.26 & 71.0832 & 42.18 & 53.9011 & -43.14 & 0.7799 \\
\hline 30 & 54.26 & 71.2754 & 42.18 & 54.1009 & -43.14 & 2.0811 \\
\hline 40 & 54.26 & 73.2817 & 42.18 & 55.2022 & -22.17 & 1.1133 \\
\hline 50 & 54.26 & 73.2817 & 42.18 & 55.2022 & 2.9 & 7.2002 \\
\hline 60 & 54.26 & 73.2817 & 42.18 & 55.2022 & 16.13 & 18.0893 \\
\hline 70 & 54.26 & 73.2817 & 42.18 & 55.2022 & 22.24 & 25.0177 \\
\hline
\end{tabular}

Table 9. Comparison of pollution mission

\begin{tabular}{|c|c|}
\hline Methods & Emission (kg) \\
\hline MFPA [15] & 222.01 \\
\hline PROPOSED FPA-IC & 214.38 \\
\hline
\end{tabular}

FPA-IC achieves better PV \& Wind power at various timings when compared with FLC-PI [19]. From the comparative analysis, it is concluded that THD is $0.71 \%$ which is less compared to MPCP-MPVP, FLC-PI, and MPPVC. Table 8 shows the comparative analysis of hybrid renewable sources with existing MPPT method [20]. From the table 8, it clearly shows that proposed FPA-IC achieves higher power when compared with existing MPPT in all the sources.

International Journal of Intelligent Engineering and Systems, Vol.15, No.2, 2022
Table 9 shows the emission of pollution for existing MFPA [15]. From the table 9, it clearly shows that proposed FPA-IC emits less pollution of $214.38 \mathrm{~kg}$ when compared with existing MFPA [15] which emits $222.01 \mathrm{~kg}$. The FPA-IC controller achieves high power optimal switching between wind and battery and obtain MPP from different load peak points. 


\section{Conclusion}

In this study, a combination of FPA-IC was used to develop an effective EMS using PV/wind/battery system. An effective switching between battery and wind was controlled by using the modulation index from FPA. Also, stable power from the gridconnected RES was obtained using the IC method by triggering the converter and capacitor banks were utilized to avoid spikes in the delivered power. FPAIC controller used in the grid-connected RES system was evaluated for various irradiance and temperature levels. The major advantage of a higher convergence rate and its addition of current change in proposed FPA-IC facilitated to creation of an effective EMS for $\mathrm{PV} /$ wind/battery system. In the comparison, the FPAIC controller showed less THD $(0.71 \%)$ when compared with the existing RES systems MPCPMPVP and MPPVC. In the future, the proposed method can be improved by considering more random and uncertain factors in the generation, load demand, and smart battery charging technology.

\section{Conflicts of Interest}

The authors declare no conflict of interest.

\section{Author Contributions}

The paper conceptualization, methodology, software, validation, formal analysis, investigation, resources, data curation, writing - original draft preparation, writing-review and editing, visualization, have been done by $1^{\text {st }}$ author. The supervision and project administration, have been done by $2^{\text {nd }}$ author.

\section{References}

[1] A. A. Jain, B. J. Rabi, and S. S. Darly, "Application of QOCGWO-RFA for maximum power point tracking (MPPT) and power flow management of solar PV generation system", International Journal of Hydrogen Energy, Vol. 45, No. 7, pp. 4122-4136, 2020.

[2] S. Salisu, M. W. Mustafa, L. Olatomiwa, and O. O. Mohammed, "Assessment of technical and economic feasibility for a hybrid PV-winddiesel-battery energy system in a remote community of north central Nigeria", Alexandria Engineering Journal, Vol. 58, No. 4, pp. 1103-1118, 2019.

[3] W. M. Hamanah, M. A. Abido, and L. M. Alhems, "Optimum Sizing of Hybrid PV, Wind, Battery and Diesel System Using Lightning Search Algorithm", Arabian Journal for Science and Engineering, Vol. 45, No. 3, pp. 1871-1883, 2020.

[4] E. N. Nyeche, and E. O., "Diemuodeke, Modelling and optimisation of a hybrid PV-wind turbine-pumped hydro storage energy system for mini-grid application in coastline communities", Journal of Cleaner Production, Vol. 250, p. 119578, 2020.

[5] N. S. Naidu and B., "Singh, Doubly fed induction generator for wind energy conversion systems with integrated active filter capabilities", IEEE Transactions on Industrial Informatics, Vol. 11, No. 4, pp. 923-933, 2015.

[6] S. A. Shezan, S. Julai, M. A. Kibria, K. R. Ullah, R. Saidur, W. T. Chong, and R. K. Akikur, "Performance analysis of an off-grid wind-PV (photovoltaic)-diesel-battery hybrid energy system feasible for remote areas", Journal of Cleaner Production, Vol. 125, pp. 121-132, 2016.

[7] J. Li, Z. Wu, S. Zhou, H. Fu, and X. P. Zhang, "Aggregator service for PV and battery energy storage systems of residential building", CSEE Journal of Power and Energy Systems, Vol. 1, No. 4, pp. 3-11, 2015.

[8] J. Abushnaf and A. Rassau, "Impact of energy management system on the sizing of a gridconnected PV/Battery system", The Electricity Journal, Vol. 31, No. 2, pp. 58-66, 2018.

[9] Z. Roumila, D. Rekioua, and T. Rekioua, "Energy management based fuzzy logic controller of hybrid system wind/photovoltaic/diesel with storage battery", International Journal of Hydrogen Energy, Vol. 42, No. 30, pp. 19525-19535, 2017.

[10] R. Bouchebbat and S. Gherbi, "A novel optimal control and management strategy of stand-alone hybrid PV/wind/diesel power system", Journal of Control, Automation and Electrical Systems, Vol. 28, No. 2, pp. 284-296, 2017.

[11] S. Zhang and Y. Tang, "Optimal schedule of grid-connected residential PV generation systems with battery storages under time-of-use and step tariffs", Journal of Energy Storage, Vol. 23, pp. 175-182, 2019.

[12] Y. Han, W. Chen, Q. Li, H. Yang, F. Zare, and Y. Zheng, "Two-level energy management strategy for PV-Fuel cell-battery-based DC microgrid", International Journal of Hydrogen Energy, Vol. 44, No. 35, pp. 19395-19404, 2019.

[13] T. Bogaraj and J. Kanakaraj, "Intelligent energy management control for independent microgrid", Sädhanā, Vol. 41, No. 7, pp. 755-769, 2016.

[14] M. Elkazaz, M. Sumner, and D. "Thomas, Energy management system for hybrid PV- 
wind-battery microgrid using convex programming, model predictive and rolling horizon predictive control with experimental validation", International Journal of Electrical Power \& Energy Systems, Vol. 115, p. 105483, 2020.

[15] M. De, G. Das, and K. K. Mandal, "An effective energy flow management in grid-connected solar-wind-micro-grid system incorporating economic and environmental generation scheduling using a meta-dynamic approachbased multi-objective flower pollination algorithm", Energy Reports, Vol. 7, pp. 27112726, 2021.

[16] S. K. Jha and D. Kumar, "Assessment of Battery Energy Storage System with Hybrid Renewable Energy Sources to Voltage Control of Islanded Microgrid Considering Demand-Side Management Capability", Iranian Journal of Science and Technology, Transactions of Electrical Engineering, Vol. 44, pp. 861-877, 2020.

[17] Y. Shan, J. Hu, K. W. Chan, Q. Fu, and J. M. Guerrero, "Model predictive control of bidirectional DC-DC converters and AC/DC interlinking converters-A new control method for PV-wind-battery microgrids", IEEE Transactions on Sustainable Energy, Vol. 10, No. 4, pp. 1823-1833, 2019.

[18] J. Hu, Y. Shan, Y. Xu, and J. M. Guerrero, “A coordinated control of hybrid ac/dc microgrids with PV-wind-battery under variable generation and load conditions", International Journal of Electrical Power \& Energy Systems, Vol. 104, pp. 583-592, 2019.

[19] K. Basaran, N. S. Cetin, and S. Borekci, "Energy management for on-grid and off-grid wind/PV and battery hybrid systems", IET Renewable Power Generation, Vol. 11, No. 5, pp. 642-649, 2017.

[20] P. S. Kumar, R. P. Chandrasena, V. Ramu, G. N. Srinivas, and K. V. S. M. Babu, "Energy management system for small scale hybrid wind solar battery based microgrid", IEEE Access, Vol. 8, pp. 8336-8345, 2020.

[21] P. P. Vergara, J. M. Rey, L. C. P. D. Silva, and G. Ordóñez, "Comparative Analysis Of Design Criteria For Hybrid Photovoltaic/wind/battery Systems", IET Renewable Power Generation, Vol. 11, No. 3, pp. 253-61, 2016. 